\title{
Anti-biofilm Activity of Chitosan from Crab and Shrimp Species Indigenous to the Philippines on Established Biofilms of Pseudomonas aeruginosa and Staphylococcus aureus
}

Berley Jane Aurestila, Erla Ann Marie Villaver ${ }^{*}$ and Elizabeth $Y$ Tan

Department of Pharmacy, University of San Carlos, Philippines

*Corresponding author: Erla Ann Marie Villaver, Department of Pharmacy, University of San Carlos, Philippines, Tel: +63-9199886591; E-mail: erlavillaver@yahoo.com Received date: January 22, 2018; Accepted date: January 29, 2018; Published date: February 01, 2018

Copyright: (c) 2018 Villaver EAM, et al. This is an open-access article distributed under the terms of the Creative Commons Attribution License, which permits unrestricted use, distribution, and reproduction in any medium, provided the original author and source are credited.

\begin{abstract}
Biofilms are structures produced by bacteria by attaching themselves together in a surface to form a protective matrix, rendering them resistant to antimicrobial treatments. The objective of this study was to examine the antibiofilm activity of chitosan from crab and shrimp species on the established biofilms of Pseudomonas aeruginosa and Staphylococcus aureus. The test groups were treated with chitosan solutions of varying concentrations $(2.5 \mathrm{~g} / \mathrm{L}$ and $10 \mathrm{~g} / \mathrm{L}$ ) chitosan from shrimp shells extract, $2.5 \mathrm{~g} / \mathrm{L}$ and $10 \mathrm{~g} / \mathrm{L}$ crab shells extract and a mixture of both shell extracts with the same concentration mixed in a one-to-one volume by ratio. Three different analysis were conducted involving color intensity test through TotalLab software, spectrophotometric analysis and microplate reader analysis. The highest percent anti-biofilm formation inhibition was observed with the $2.5 \mathrm{~g} / \mathrm{L}$ mixed (1:1) chitosan solution against established biofilms of $P$. aeruginosa with a $62.90 \pm 12 \%$ inhibition. On the other hand, $S$. aureus showed no percent inhibition with the $2.5 \mathrm{~g} / \mathrm{L}$ shrimp chitosan and $10 \mathrm{~g} / \mathrm{L}$ crab chitosan but was most sensitive to $10 \mathrm{~g} / \mathrm{L}$ mixed (1:1) chitosan solution with an inhibition of $39.47 \pm 19 \%$. From the results, the $1: 1$ combination of shrimp and crab chitosan solutions resulted to a higher percent anti-biofilm formation inhibition than when given separately.
\end{abstract}

Keywords: Biofilm formers; Chitosan; Crabs; Shrimps

\section{Introduction}

According to the World Health Organization (2016), antimicrobial resistance continues to be a global problem due to wide range of infections caused by bacteria, virus, fungi or parasites. Microorganisms develop certain mechanisms to counteract the medical treatments such as the enzymatic inactivation of the antibiotic or alteration and modification of the antibiotic target site which would render the antibiotic useless [1]. As a result, patient's illness would be prolonged and there would be difficulties in curing the acquired infection. Biofilm formation is one of the mechanisms acquired by microbes to counterattack the effects of the antibiotics at hand. Biofilms are structures produced by bacteria by attaching themselves together in a surface (inert or living) to form a protective matrix. To address this problem, this study was conducted to combat the microbial biofilms formed by destroying it permanently. As a result of this, the microbe will then be exposed and will be susceptible to any antimicrobial agent which leads to the death of the microbial cell.

Not all microorganisms are capable of forming biofilms. Pseudomonas aeruginosa, a Gram-negative bacterium, is known to be resistant to antibiotic treatments due to formation of biofilms. This opportunistic pathogenic bacterium is known to be responsible for various infections, particularly in immunocompromised patients [1]. Another bacterium capable of biofilm formation is the Staphylococcus aureus. $S$. aureus is considered to be the most frequent cause of nosocomial infections and infections on indwelling medical devices along with $S$. epidermidis [2]. These two pathogenic bacteria were the focus of this research due to the different studies conducted that proved the ability of the bacteria to form biofilms $[3,4]$. Also, they pose a serious threat which would lead to chronic infections that are not susceptible to any treatments leading to long-lasting infections or even death.

Chitosan is a polysaccharide derived from chitin and is abundant in crustaceans. It is found to have a broad antimicrobial activity against a wide range of microorganisms [5]. Being a natural polysaccharide, chitosan exhibits notable biological properties including non-toxicity and biocompatibility which makes it a good candidate for biomedical applications [6]. This led to studies on chitosan being an effective antibiofilm agent by penetrating biofilms present, particularly in medical devices. By doing so, chitosan will be able to disrupt the microbial cell membrane [7]. Thus, biofilm formation will be inhibited due to the disruption of the attachment of the bacteria's cell membrane to the solid surfaces. By destroying the biofilm, the bacteria will then be susceptible to antibiotics which will consequently lead to bacterial cell death.

The objective of this study was to examine the anti-biofilm activity of chitosan from crab and shrimp species on the established biofilms of Pseudomonas aeruginosa and Staphylococcus aureus.

\section{Limitations of the study}

This study was done with limitations during the experimental procedures due to the availability of the resources. The degrees of deacetylation of the chitosan samples were not determined. The chitosan samples were only stored in a regular transparent containers and were placed in a refrigerator without controlling temperature. There were only two concentrations $(2.5 \mathrm{~g} / \mathrm{L}$ and $10 \mathrm{~g} / \mathrm{L})$ used for this particular study. 
Citation: Aurestila BJ, Villaver EAM, Tan EY (2018) Anti-biofilm Activity of Chitosan from Crab and Shrimp Species Indigenous to the Philippines on Established Biofilms of Pseudomonas aeruginosa and Staphylococcus aureus. J Pharmacogn Nat Prod 4: 149. doi: $10.4172 / 2472-0992.1000149$

Page 2 of 5

\section{Materials and Methods}

Staphylococcus aureus and Pseudomonas aeruginosa were treated separate. Three trials were conducted in triplicates. Two chitosan extracts were used as the treatment for the test groups in the experiment: crab chitosan extract, shrimp chitosan extract and a mixture of both in a one-to-one volume by ratio. Two concentrations were prepared for each extract $(2.5 \mathrm{~g} / \mathrm{L}$ and $10 \mathrm{~g} / \mathrm{L})$. Acetic acid was used for the treatment of the control group.

\section{Extract preparation}

Extraction of chitosan from Blue Swimming crab and Whiteleg shrimp was done separately. For the extraction of chitosan from Whiteleg shrimp, the shells were washed, air dried and refrigerated overnight. It was then oven dried for 4 days at $65^{\circ} \mathrm{C}$. After, it was treated with $2000 \mathrm{~mL}$ of $4 \% \mathrm{NaOH}$ at room temperature for 24 hours. The deproteinization of Whiteleg shrimp shells was done by draining the alkali solution from the shells and the shells were washed with distilled water repeatedly until the $\mathrm{pH}$ turned neutral. The deproteinized shells were then treated with $2000 \mathrm{~mL}$ of $4 \% \mathrm{HCl}$ for 12 hours for demineralization to yield chitin. The resulting acid solution was drained off from chitin, washed with distilled water and dried at room temperature. The processes were repeated with $2000 \mathrm{~mL}$ of $2 \%$ $\mathrm{NaOH}$ and $2000 \mathrm{~mL}$ of $1 \% \mathrm{HCl}$. Further decolorization of the chitin was obtained by soaking it in $2000 \mathrm{~mL}$ of $1 \% \mathrm{KMnO}_{4}$ for 30 minutes followed by $2000 \mathrm{~mL}$ of $1 \%$ oxalic acid for 30 minutes to 2 hours. The decolorized chitin was then deacetylated to form chitosan by treating with $2000 \mathrm{~mL}$ of $65 \% \mathrm{NaOH}$ for 3 days at room temperature. The alkali solution was drained off and washed repeatedly with distilled water until the $\mathrm{pH}$ was neutral. The extracted chitosan was further dried at room temperature [8].

The extraction of chitosan from blue swimming crab was done using the procedure by Sujeetha et al., 2015. The blue swimming crab shells were washed thoroughly in running tap water to remove the debris and were sun dried. The sun dried shells were then crushed and soaked in $4000 \mathrm{~mL}$ of $9 \% \mathrm{HCl}$ in the ratio 1:14 for 40 hours at room temperature. After, $4000 \mathrm{~mL}$ of $5 \% \mathrm{NaOH}$ was used for further treatment. After the neutralization process, it was then sun dried for two days and was grounded afterwards. The deacetylation process was done using $4000 \mathrm{~mL}$ of $70 \% \mathrm{NaOH}$ solution in a ratio of 1:15 (w/v) for 72 hours at room temperature. The resulting mixture was then filtered and was oven dried at $80^{\circ} \mathrm{C}$ [9].

\section{Preparation of chitosan treatments}

The chitosan was dissolved in acetic acid. To make the $2.5 \mathrm{~g} / \mathrm{L}$ chitosan solution, $0.5 \mathrm{~g}$ of the chitosan was dissolved in $250 \mathrm{~mL}$ of 0.1 $\mathrm{M}$ of acetic acid. $2.5 \mathrm{~g}$ of the chitosan was dissolved in $250 \mathrm{~mL}$ of $0.1 \mathrm{M}$ of acetic acid to make $10 \mathrm{~g} / \mathrm{L}$ chitosan solution. The chitosan solution was then stirred for 8 hours using a magnetic stirrer set at $55^{\circ} \mathrm{C}, 100$ $\mathrm{rpm}$. Afterwards, the solution was filtered using cheesecloth to remove the impurities. The solution was then stored inside the refrigerator.

\section{Growing bacteria culture}

The microorganisms from the agar slant, which is the source of the bacteria, were allowed to grow in nutrient broth. The nutrient broth served as a media for the bacteria to grow, which was then used in the in the determination of the bacterial population and in the preparation for the biofilms on the microtiter plates.
Ten milliliters of broth was transferred to each of the test tube. $P$. aeruginosa and $S$. aureus were then inoculated under laminar flow hood, following aseptic technique. The bacterial cultures were then incubated for $24 \mathrm{~h}$ at $37 \mathrm{C}$ and were allowed to grow.

\section{Determination of bacterial population}

Serial dilution was done to determine the bacterial population in the liquid culture. After serial dilution, one hundred microliters was then pipetted into agar plates and was allowed to grow in the incubator for three days at $27^{\circ} \mathrm{C}$. An estimation of the number of bacteria per $\mathrm{mL}$ of the original culture or Colony forming unit (CFU) was then computed using the same method as the study by Ednalino et al. (2012), which used the equation:

No. of bacteria $(\mathrm{CFU}) / \mathrm{mL}$ in original culture $=($ No. of colonies diluted $) \times($ Dilution factor of volume plated $) \times($ Dilution factor for the dilution of the plate).

\section{Preparation of biofilm on microtiter plates}

Biofilms were cultured in a 96-well microplate. Twenty one wells were used and filled with one hundred microliter $(100 \mu \mathrm{L})$ of the diluted culture of $S$. aureus. One hundred microliter $(100 \mu \mathrm{L})$ of the diluted culture of $P$. aeruginosa was used to fill another twenty one wells of the microplate. The microtiter plate was covered and was placed in an incubator for six days at $37^{\circ} \mathrm{C}$.

\section{Application of chitosan treatments}

Two concentrations of the chitosan solution were prepared ( $2.5 \mathrm{~g} /$ $\mathrm{L}$ and $10 \mathrm{~g} / \mathrm{L}$ ) from the shrimp shells extract, crab shells extract and with both shell extracts mixed in a one-to-one ratio by volume.

One hundred microliter of each concentration was introduced into 42 wells, with three wells allotted for each concentration per bacteria. This served as the test group (or assay group). One hundred microliter of acetic acid was then pipetted onto three wells for each microorganism that served as the control group. The microtiter plate was covered with the lid, sealed and placed inside an incubator at $37^{\circ} \mathrm{C}$ for 4 days.

\section{Evaluation and analysis of biofilms}

Biofilm quantification was carried out resembling the procedures done by Costa et al., 2014. The contents from the wells was discarded and washed three times with sterile water in order to visualize the adhesion of the biofilm as well as to remove the non-adherent cells. $200 \mu \mathrm{L}$ of ethanol was then added to the wells to ensure the fixed attachment of the remaining microorganisms at the surface of the wells. After 15 minutes, ethanol was discarded and the wells were airdried. After the drying procedure, $200 \mu \mathrm{L}$ of crystal violet solution was added to the wells for 5 minutes. Excess stain was removed by rinsing the plate with water and air drying was followed.

The microplate was then subjected in a microplate reader in order to measure the optical density at $625 \mathrm{~nm}$. The degree of biofilm formation inhibition was calculated using the equation by Costa et al., 2014.

$\%$ Biofilm Formation Inhibition $=100-\left(\mathrm{OD}_{\text {assay }} / \mathrm{OD}_{\text {control }}\right) \times 100$

Where $\mathrm{OD}_{\text {assay }}$ is the optical density of the test group and $\mathrm{OD}_{\text {control }}$ is the optical density of the control group. 
Citation: Aurestila BJ, Villaver EAM, Tan EY (2018) Anti-biofilm Activity of Chitosan from Crab and Shrimp Species Indigenous to the Philippines on Established Biofilms of Pseudomonas aeruginosa and Staphylococcus aureus. J Pharmacogn Nat Prod 4: 149. doi: $10.4172 / 2472-0992.1000149$

Page 3 of 5

The microplate was also subjected to a qualitative analysis. It was then scanned using a printer with a resolution of $600 \mathrm{dpi}$. Using the digital images obtained, the biofilms were evaluated using image analysis software called TotalLab Array v10 software.

The results were analyzed based from the color intensities which were measured in pixels per inch (ppi). It is the pixel density that will determine the color intensity of the stain. The intensity of the color of each well is proportional to the biofilm present in the solution.

A spectrophotometer was also used to quantify and validate the results by measuring the absorbance of the solutions. $125 \mu \mathrm{L}$ of the solution from the wells was then transferred to the cuvettes. It was then diluted with $3 \mathrm{~mL}$ of $95 \%$ ethanol. The spectrophotometer was then set at $435 \mathrm{~nm}$ for the absorbance of the violet color and each of the cuvette was analyzed for its absorbance values. Absorbance reflected in the instrument will be used as measures of the effectiveness of the treatment especially when compared to the baseline (Ednalino et al., 2012).

\section{Statistical analysis}

Two-way ANOVA with a significance level of 0.01 and 99\% CL was used to determine the effectiveness of different chitosan solutions from $P$. pelagicus, $P$. vannamei, and the mixture of both in a one-to-one ratio by volume against $S$. aureus and $P$. aeruginosa biofilms. Two independent factors were determined to be the absorbance values and the percent formation inhibition activity of the chitosan. In ANOVA, the null hypothesis states that there is no significant difference in the mean pixel densities of the treatments. The alternative hypothesis states that the mean pixel densities of the treatments has a significant difference.

The correlation coefficient between the absorbance values and the color intensity values was also determined to quantify the relationship between these two parameters.

\section{Results}

Chitosan extracted from shrimp shells which are white and flaky solid material. On the other hand, the chitosan extracted from crab shells which are light orange and hard solid material.

To verify verifies the presence of the chitosan from both shrimp and crab shell samples. Chitosan was added with Lugol's iodine solution and resulted to a yellowish-brown material. Upon addition of the $\mathrm{H}_{2} \mathrm{SO}_{4}$, the color changed to red-violet. Bacterial population determination through serial dilution revealed that that the tenth plate of Staphylococus aureus with a dilution factor of 10 was found to contain 208 colonies and $2.08 \times 1011$ CFU's. On the other hand, the tenth plate of Pseudomonas aeruginosa with a dilution factor of 10 was found to contain 54 colonies and $5.40 \times 1010$ CFU's.

\section{Color intensity test}

Figure 1 shows the color intensities of the violet stains of Staphylococus aureus biofilms. As compared to the one treated with $0.1 \mathrm{M}$ acetic acid (control group) which has $11673 \pm 16318.51 \mathrm{ppi}$, the least color intensity value was seen in the wells treated with $10 \mathrm{~g} / \mathrm{L}$ of crab chitosan for $\mathrm{S}$. aureus which has $87.57 \pm 43.10$ ppi. It was followed by the one treated with $2.5 \mathrm{~g} / \mathrm{L}$ mixed $(1: 1)$ chitosan solution with $209.44 \pm 182.59 \mathrm{ppi}$. The $2.5 \mathrm{~g} / \mathrm{L}$ crab chitosan solution followed which has $617.0 \pm 664.66 \mathrm{ppi}$. The $S$. aureus biofilms treated with $10 \mathrm{~g} / \mathrm{L}$ mixed (1:1) chitosan solution followed which has $1883 \pm 2269.88$ ppi.
The well containing $S$. aureus biofilms treated with $2.5 \mathrm{~g} / \mathrm{L}$ shrimp chitosan solution has the highest color intensity value which has 11411 \pm 15350.93 ppi.

The color intensities of the violet stains of Pseudomonas aeruginosa for the different chitosan types and concentrations were shown in Figure 1 . The graph below shows the least color intensity value which was seen in the well treated with $10 \mathrm{~g} / \mathrm{L}$ of crab chitosan having $87.81 \pm$ $81.47 \mathrm{ppi}$ as compared to the one treated with $0.1 \mathrm{M}$ acetic acid (control group) which has $17244 \pm 24274.01 \mathrm{ppi}$. It was then followed with the well treated with $2.5 \mathrm{~g} / \mathrm{L}$ mixed (1:1) chitosan solution with $446.52 \pm 461.83$ ppi.

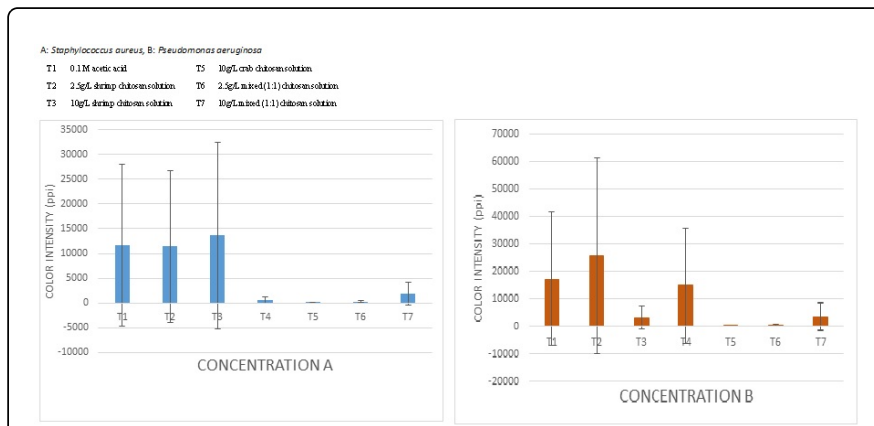

Figure 1: Color intensities of the violet stain of $S$. aureus and $P$. aeruginosa biofilms after application of the different chitosan solutions.

Figure 1 also depicts that the well treated with $2.5 \mathrm{~g} / \mathrm{L}$ shrimp chitosan solution has the highest color intensity value which was 25563 \pm 35492.16 ppi. $2.5 \mathrm{~g} / \mathrm{L}$ crab chitosan solution follows with a color intensity value of $14783 \pm 20821.70 \mathrm{ppi}$. This was then followed by $3558.3 \pm 4948.06$ ppi which was exhibited by the well treated with 10 $\mathrm{g} / \mathrm{L}$ mixed (1:1) chitosan solution. The $10 \mathrm{~g} / \mathrm{L}$ shrimp chitosan solution followed with a color intensity of $3267 \pm 4292.34$ ppi.

\section{Microplate reader analysis}

From the results of the microplate reader analysis, optical densities of each well were determined. Following the equation by Costa et al., the percent biofilm formation inhibition of each chitosan solution against $S$. aureus and $P$. aeruginosa was calculated as shown in Figure 2 .

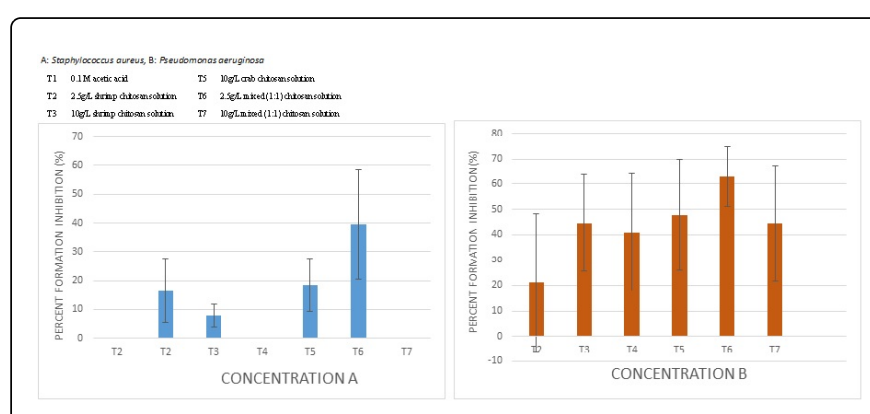

Figure 2: Percent anti-biofilm formation inhibition of different chitosan solutions against $S$. aureus and $P$. aeruginosa biofilms.

The $2.5 \mathrm{~g} / \mathrm{L}$ shrimp chitosan and $10 \mathrm{~g} / \mathrm{L}$ crab chitosan showed no activity against $S$. aureus. In the case of $P$. aeruginosa biofilms, the 2.5 
Citation: Aurestila BJ, Villaver EAM, Tan EY (2018) Anti-biofilm Activity of Chitosan from Crab and Shrimp Species Indigenous to the Philippines on Established Biofilms of Pseudomonas aeruginosa and Staphylococcus aureus. J Pharmacogn Nat Prod 4: 149. doi: $10.4172 / 2472-0992.1000149$

Page 4 of 5

$\mathrm{g} / \mathrm{L}$ of shrimp chitosan exhibited the least activity against the bacteria having $21.18 \pm 27 \%$ anti-biofilm formation inhibitions.

The $2.5 \mathrm{~g} / \mathrm{L}$ mixed (1:1) chitosan solution has $18.42 \pm 9 \%$ and 62.90 $\pm 12 \%$ biofilm formation inhibition against $S$. aureus and $P$. aeruginosa, respectively. On the other hand, $39.47 \pm 19 \%$ and $44.55 \pm$ $23 \%$ biofilm formation inhibition were demonstrated by $10 \mathrm{~g} / \mathrm{L}$ mixed (1:1) chitosan solution against $S$. aureus and $P$. aeruginosa, respectively. Based from the results, the two mixtures of the chitosan solution from shrimp and crab shells in two different concentrations were found to have a higher percent anti-biofilm formation inhibition.

\section{Spectrophotometric analysis results}

Figure 3 shows the absorbance values of the violet stains of $S$. aureus and $P$. aeruginosa biofilms, respectively, after the chitosan treatment. The one treated with $2.5 \mathrm{~g} / \mathrm{L}$ mixed (1:1) chitosan solution has the lowest absorbance which has $0.065 \pm 0.000471$ for $S$. aureus while $0.065 \pm 0.00216$ for $P$. aeruginosa. This means that $2.5 \mathrm{~g} / \mathrm{L}$ mixed $(1: 1)$ chitosan solution effectively destroyed the established biofilms of both bacteria.

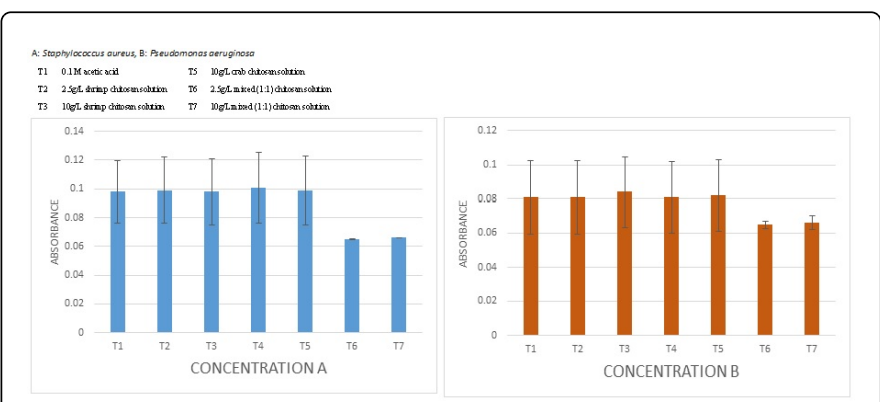

Figure 3: Absorbance of the violet stain of $S$. aureus and $P$. aeruginosa biofilms after application of different chitosan solutions.

$S$. aureus biofilms treated with $0.1 \mathrm{M}$ acetic acid (control group) has the absorbance of $0.098 \pm 0.022$ as depicted in Figure 3. When compared to the control group, no activity was seen in $2.5 \mathrm{~g} / \mathrm{L}$ shrimp chitosan solution and $10 \mathrm{~g} / \mathrm{L}$ crab chitosan solution against $S$. aureus biofilm, which has $0.099 \pm 0.023$ and $0.099 \pm 0.024$ respectively.

In Figure 3, $10 \mathrm{~g} / \mathrm{L}$ shrimp chitosan showed no activity against established biofilms of $P$. aeruginosa. Its absorbance is $0.084 \pm 0.021$ which is higher compared to the control group which has the absorbance of $0.081 \pm 0.022$.

\section{Statistical analysis results}

\begin{tabular}{|l|l|l|l|l|l|l|}
\hline Source of variation & SS & df & MS & F & $\begin{array}{l}\text { P- } \\
\text { value }\end{array}$ & F crit \\
\hline Chitosan type & 216.184 & 6 & 36.031 & $\begin{array}{l}0.85 \\
6\end{array}$ & 0.538 & $\begin{array}{l}3.47 \\
3\end{array}$ \\
\hline $\begin{array}{l}\text { Absorbance and percent } \\
\text { inhibition activity }\end{array}$ & 977.125 & 5 & $\begin{array}{l}195.42 \\
5\end{array}$ & $\begin{array}{l}4.64 \\
4\end{array}$ & 0.003 & $\begin{array}{l}3.68 \\
8\end{array}$ \\
\hline Error & 1262.355 & 30 & 42.079 & - & - & - \\
\hline Total & 2455.664 & 41 & - & - & - & - \\
\hline
\end{tabular}

Table 1: Two-way ANOVA analysis for $S$. aureus.
Tables 1 and 2 show the two-way ANOVA analysis results. For the chitosan type, the p-value is greater than 0.01 for both $S$. aureus and $P$. aeruginosa. For this particular study, the chitosan type and concentration is considered to be insignificant.

\begin{tabular}{|l|l|l|l|l|l|l|}
\hline Source of variation & SS & df & MS & F & $\begin{array}{l}\text { P. } \\
\text { value }\end{array}$ & $\begin{array}{l}\text { F } \\
\text { crit }\end{array}$ \\
\hline Chitosan type & 3802.645 & 6 & 63.774 & 3.235 & 0.014 & $\begin{array}{l}3.47 \\
3\end{array}$ \\
\hline $\begin{array}{l}\text { Absorbance and percent } \\
\text { Inhibition activity }\end{array}$ & 21064.026 & 5 & $\begin{array}{l}4212.80 \\
5\end{array}$ & $\begin{array}{l}21.50 \\
5\end{array}$ & $\begin{array}{l}4.213- \\
9\end{array}$ & $\begin{array}{l}3.69 \\
9\end{array}$ \\
\hline Error & & & 195.899 & & & \\
\hline Total & 5876.969 & 30 & & & & \\
\hline
\end{tabular}

Table 2: Two-way ANOVA analysis for $P$. aeruginosa.

On the other hand, the p-value between absorbance and percent formation inhibition values for both bacteria is less than 0.01 which is significant.

The correlation coefficient between the absorbance and color intensity values is 0.459 (as depicted in Table 3 ) while the p-value is 0.042 . These two parameters have insignificant positive correlation.

\begin{tabular}{|l|l|l|}
\hline & Absorbance & Color intensity \\
\hline Absorbance & 1 & 0.459113177 \\
\hline Color intensity & 0.459113177 & 1 \\
\hline
\end{tabular}

Table 3: Determination of the correlation coefficient between absorbance and color intensity.

\section{Discussion}

Chitosan was extracted through three major processes which include deproteinization, demineralization and deacetylation. Deacytelation is the last procedure in the extraction of chitosan. It is a process that would convert chitin to chitosan $[10,11]$.

To test for the biofilms left after chitosan treatment, color intensity test through TotalLab Image Analysis and spectrophotometric analysis were conducted. According to a study conducted by Ednalino et al. (2012), the amount of biofilm is proportional to the color intensity and the absorbance of the well.

The optical density analysis through microplate reader was done to calculate the percent biofilm formation inhibition of the different chitosan solutions. Based from the results shown in Figure 2, P. aeruginosa biofilms are more susceptible to chitosan treatment when compared to $S$. aureus. In a study conducted by Orgaz et al., Pseudomonas biofilms are highly susceptible against chitosan treatment even though it has thick matrix [12].

Based from the results of the spectrophotometric analysis and the validation through microplate reader, the two mixtures of the chitosan solution from shrimp and crab shells in two different concentrations (both crab and shrimp chitosan mixed in 1:1 by volume) were found to be more effective in the inhibition of the $S$. aureus and $P$. aeruginosa biofilms. The insufficient results for the chitosan inhibition of $S$. aureus 
Citation: Aurestila BJ, Villaver EAM, Tan EY (2018) Anti-biofilm Activity of Chitosan from Crab and Shrimp Species Indigenous to the Philippines on Established Biofilms of Pseudomonas aeruginosa and Staphylococcus aureus. J Pharmacogn Nat Prod 4: 149. doi: $10.4172 / 2472-0992.1000149$

Page 5 of 5

biofilms can be explained because of the ability of $S$. aureus to produce a multilayered biofilm which is embedded within a glycocalyx [13]. It is generally known that biofilm-embedded cells are protected from certain conditions that may be damaging to a cell, such as lack of water or nutrients or even if an antimicrobial agent is introduced into it [12]. With these mechanisms, it will be difficult for the chitosan to penetrate the matrix of the bacteria resulting to insusceptibility.

The variety of chitosan and the different concentrations are considered to be insignificant in this study. This can be attributed to the fact that both chitosan sources are marine crustaceans which produce $\alpha$-chitin in general [14]. Chitin can be subdivided according to the derived material: $\alpha$-chitin, $\beta$-chitin and $\gamma$-chitin [15]. $\alpha$-chitin can be extracted from marine crustaceans, arthropods, fungi and the cysts of Entamoea while $\beta$-chitin can be seen from the pen of the Loligo squid. $\gamma$-chitin is very rare and it can only be extracted from cocoon fibers of the Ptinus beetle and the stomach of the Loligo squid [14].

On the other hand, the absorbance values and percent formation inhibition values are considered to have a significant correlation. The significant difference reflected in the statistical analysis can be attributed to the inverse relationship of the two parameters.

For this particular study, absorbance values and color intensity values have insignificant positive correlation. This means that the two parameters have a direct relationship with each other. The BeerLambert Law states that the absorbance is proportional to the concentration, which was measured with the color intensity test, and the path length through which the light passes through the sample [2].

\section{Conclusion}

The study concluded that Pseudomonas aeruginosa appeared to be more sensitive to the chitosan treatments than Staphylococcus aureus. It has been demonstrated that the hydrophilicity in gram-negative bacteria is significantly higher than in gram-positive bacteria. This, in turn, makes $P$. aeruginosa, a gram-negative bacterium, more sensitive to chitosan. $S$. aureus also forms a multilayered biofilm making it more difficult for the chitosan treatment to penetrate its biofilm. Also, the study concluded that the 1:1 combination of shrimp and crab chitosan solutions resulted to a higher percent anti-biofilm formation inhibition than when given separately.

\section{Acknowledgement}

The researchers would like to acknowledge the Department of Pharmacy at the University of San Carlos and its faculty members for the assistance in the accomplishment of this study. This research would also not be possible without the expertise and guidance of the adviser, Mrs. Elizabeth Y. Tan, along with the panel members of the study: Ms. Glenda Gay Abapo, Dr. Anthony Ilano, Dr. Noel Roble, Mrs. Nelly Nonette Ouano and Mrs. Jacklyn San Gabriel. The researchers would also like to recognize Ms. Kimberly Ednalino for imparting her knowledge regarding some aspects of the study. Also, the experimentation of this study in the laboratory would not be possible without the help of Mr. Marssus G. Lamagon and Mr. Arnel P. Casas.
Moreover, the analysis of this study would not be completed without the help of Dr. Ramon S. del Fierro and Mr. Harold Menchavez of Tuklas Lunas Development Center at the University of San Carlos, and to Mr. Glen Mark Piañar for the assistance in the statistical analysis of this research. Finally, the researchers would like to acknowledge our families for their unrelenting support and to the Almighty God who have unconditional love and guidance until the completion of the study.

\section{References}

1. Rasamiravaka T, Labtani Q, Duez P, El Jaziri M (2014) The formation of biofilms by Pseudomonas aeruginosa: A review of the natural and synthetic compounds interfering with control mechanisms. BioMed Res Int 2015: 1-17.

2. Otto M (2008) Staphylococcal biofilms. Curr Top Microbiol Immunol 322: $207-228$.

3. Jefferson K (2004) What drives bacteria to produce a biofilm? FEMS Microbiol Lett 236: 163-173.

4. Periasamy S, Hwang S, Duong A, Bach T, Tan V, et al. (2011) How Staphylococcus aureus biofilms develop characteristic structure. Proc Natl Acad Sci USA 109: 1281-1286.

5. Goy R, Britto D, Assis O (2009) A review of the antimicrobial activity of chitosan. Polímeros: Ciência e Tecnologia 19: 241-247.

6. Silva-Dias A, Palmeira-de-Oliveira A, Miranda I, Branco J, Cobrado L, et al. (2014) Anti-biofilm activity of low-molecular weight chitosan hydrogel against candida species. Med Microbiol Immunol 203: 25-33.

7. Zhang A, Mu H, Zhang W, Cui G, Zhu J, et al. (2013) Chitosan coupling makes microbial biofilms susceptible to antibiotics. Scientific Reports 2013: 1-7.

8. Divya K, Rebello S, Jisha M (2014) A simple and effective method for extraction of high purity chitosan from shrimp shell waste. 2014 Proceeding of International Conference on Advances in Applied Science and Environmental Engineering, pp: 141-145.

9. Sujeetha M, Sharmila S, Jayanthi J, Ragunathan MG (2015) Quantitative and qualitative analysis of chitin and chitosan from the shell of the Mud Crab, Scylla serrata (Forskal, 1775). International Journal of Pharmacy and Therapeutics 6: 69-72.

10. Costa E, Silva S, Tavaria F, Pintado M (2014) Antimicrobial and antibiofilm activity of chitosan on the oral pathogen Candida albicans. Pathogens 3: 908-919.

11. Puvvada YS, Vankayalapati S, Sukhavasi S (2012) Extraction of chitin from chitosan from exoskeleton of shrimp for application in the pharmaceutical industry. International Current Pharmaceutical Journal 1: 258-263.

12. Orgaz B, Lobete M, Puga C, San Jose C (2011) Effectiveness of chitosan against mature biofilms formed by food related bacteria. Int J Mol Sci 12: 817-828.

13. Archer N, Mazaitis M, Costerton J, Leid J, Powers M, et al. (2011) Staphylococcus aureus biofilms: Properties, regulation and roles in human disease. Virulence 2: 445-459.

14. Jang M, Kong B, Jeong Y, Lee C, Nah J (2004) Physicochemical characterization of $\alpha$-chitin, $\beta$-chitin and $\gamma$-chitin Separated from natural resources. J Poly Sci 42: 3423-3432.

15. Aranaz I, Mengibar M, Harris R, Paños I, Miralles B, et al. (2009) Functional characterization of chitin and chitosan. Curr Chem Biol 3: 203-230. 